\title{
Fragilização Institucional do Planejamento Governamental e o Distanciamento EngaJado dA DiEst/IPEA ${ }^{1}$
}

Leandro Freitas Couto ${ }^{2}$

Álvaro Pontes Magalhães Júnior ${ }^{3}$

\section{INTRODUÇÃO}

O planejamento governamental do governo federal assistiu na última década um processo de intensa fragilização institucional, alcançando os órgãos governamentais responsáveis pela coordenação do Sistema de Planejamento e de Orçamento Federal, e mesmo o Plano Plurianual (PPA). Ao mesmo tempo, várias mudanças nas regras que orientam os orçamentos afetaram o espaço do planejamento no arranjo de governança orçamentária, que parece estar sendo substituído por uma agenda de governança pública.

O objetivo deste artigo é apresentar como a Diretoria de Estudos e Políticas do Estado, das Instituiçôes e da Democracia (Diest) do Ipea acompanhou essa trajetória do planejamento governamental, por meio da sua produção de pesquisa aplicada. Para cumprir tal roteiro, este artigo se dividirá em três partes, além desta introdução. Na seção 2 , serão apresentadas, de forma sucinta, as principais mudanças dos processos de planejamento e orçamento federal no Brasil, durante a década 2010/2020. Em seguida, serão destacadas as publicaçôes, entre Texto para Discussão e livros da safra da Diest ao longo da sua existência, que dialogam diretamente com os processos apresentados. À guisa de conclusão, serão destacados os principais pontos de atenção em que o Ipea, por meio da Diest, buscou apontar caminhos que aprimorassem as escolhas governamentais.

\section{A TRAJETÓRIA DE FRAGILIZAÇÃO DO PLANEJAMENTO GOVERNAMENTAL NA ÚLTIMA DÉCADA}

O momento em que o Ipea, como órgão específico do Sistema de Planejamento e de Orçamento Federal $^{4}$ (SPOF), vê reforçada a sua estrutura, com a criaçáo da Diest, é também um momento muito profícuo no planejamento governamental, particularmente na recuperação de instituições e processos de planejamento setorial e também na formação de arranjos de promoção de coordenação da ação governamental, como a criação da Secretaria do Programa de Aceleração do Crescimento (PAC), no Ministério do Planejamento, Orçamento e Gestão (De Toni, 2018; Couto e Magalhães Júnior, 2018; Cardoso Júnior e Gimenez, 2011). Todavia, do ponto de vista da institucionalidade do planejamento governamental, este também é um momento que apresenta contradiçóes.

1. DOI: http://dx.doi.org/10.38116/bapi29art8

2. Analista de planejamento e orçamento na Diest//pea.

3. Especialista em políticas públicas e gestão governamental e mestre em políticas públicas pela Universidade Federal do Rio Grande do Sul (UFRGS). Ex-integrante do corpo técnico da Diest.

4. A Lei no 10.180/2001 institui o Sistema de Planejamento e de Orçamento Federal, destacando, em seu art. 3ㅇ, que o sistema compreenderia as atividades de elaboração, acompanhamento e avaliação de planos, programas e orçamentos; e de realização de estudos e pesquisas socioeconômicas. Em seu artigo 4, indica que os órgãos específicos do sistema são aqueles vinculados ou subordinados ao órgão central, 0 Ministério do Planejamento, cuja missão fosse voltada para as atividades de planejamento e orçamento. 0 Ipea era responsável pela realização de estudos e pesquisas socioeconômicas, como órgão vinculado ao ministério, logo, comporia o sistema como órgão específico. 
Enquanto algumas funções de planejamento relacionadas à definição e gestão estratégica de prioridades eram deslocadas para a Casa Civil da Presidência da República, acompanhadas do fortalecimento do planejamento setorial, ocorre uma fragilização das capacidades de articulação e coordenação geral no âmbito do SPOF (Couto e Magalhães Júnior, 2017). Com relação aos seus instrumentos, o período assiste mudanças substantivas no PPA, que ampliaram o distanciamento entre planejamento e orçamento. No início do período, como demonstram Couto e Magalhães Júnior (2017), o PPA 2008-2011 restou esvaziado das suas funçóes, com a desativação da Comissão de Monitoramento e Avaliação, a perda da gestão estratégica de programas prioritários (o que já tinha ocorrido no PPA anterior), a fragilização dos processos participativos no âmbito da gestão do plano, bem como o abandono das iniciativas de gestão territorial (Couto e Cardoso Júnior, 2020).

Em 2011, há uma reformulação metodológica do PPA para o período 2012-2015, que pretendia aproximar o instrumento dos planejamentos e das políticas públicas setoriais, em um processo de legitimação política do PPA em relação ao próprio governo, permitindo maior flexibilidade nas declaraçôes de objetivos e metas das políticas, organizadas agora em programas temáticos. Ainda, as ações orçamentárias deixaram de fazer parte do PPA, e a ligação com o orçamento passou a se dar através da categoria iniciativa, que deveria revelar "entregas" à sociedade, muitas vezes agregando várias ações orçamentárias, o que possibilitou um movimento de aglutinação de açôes, ocorrido em 2013. A intenção era flexibilizar a execução orçamentária das políticas, o que já aparecia na agenda pública desde os documentos fundadores da reforma do aparelho do Estado, de 1995 (Couto e Cardoso Júnior, 2020; Santos, Ventura e Neto, 2015).

Esse movimento gerou críticas de entidades da sociedade civil, por representar perda de transparência nas categorias de orçamento público, objeto de monitoramento social. A frágil ligação com o PPA também ensejou críticas dos órgãos de controle, tendo em vista as dificuldades de se estabelecerem relaçóes diretas entre recursos (orçamentários e financeiros) e as metas de governo; e entre as metas, objetivos e os indicadores dos programas temáticos.

$\mathrm{Na}$ segunda metade da década, o orçamento também observou mudanças que, ao mesmo tempo em que preservavam os gastos financeiros, enrijeciam o gasto primário e resguardavam um grau de prioridade ao Poder Legislativo na definição do orçamento. Nesse sentido, observamos a aprovação de Emendas à Constituição (EC) que impunham a obrigatoriedade de execução das emendas parlamentares, individuais e de bancada, assim como limites para expansão do gasto primário, que preservavam intactos os gastos financeiros, ${ }^{5}$ limitando os espaços de influência do planejamento ou, mais ainda, da própria sociedade civil.

Deve-se destacar aqui a EC n⿳0 95/2016, que institui um novo regime fiscal para o Brasil para os próximos vinte anos - cabendo revisão ao décimo ano. A EC limita a expansão do gasto primário à inflação dos doze meses encerrados em junho do ano anterior ao que se refere à lei orçamentária, tendo como base o gasto realizado em 2016. Diante das incertezas e discussóes geradas pela crise da pandemia da Covid-19, com relação aos seus impactos fiscais, a equipe econômica do governo Bolsonaro reforçou o teto de gastos, instituído pela EC no 95/2016, como a âncora fiscal do governo, deixando de se comprometer com um resultado primário fixo.

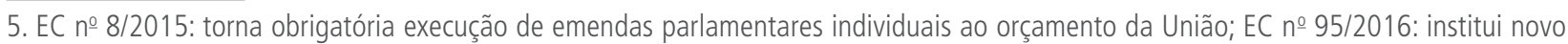
regime fiscal no Brasil para os próximos vinte anos; EC no 100/2019: torna obrigatória a execução de emendas parlamentares ao orçamento da União provenientes de bancadas estaduais. 
Ademais, durante os últimos anos da década em análise, buscou-se fortalecer a agenda de avaliação, compreendida aqui como elemento intrínseco à gestão e, portanto, ao próprio planejamento governamental. Ainda em 2016, nos estertores do governo Dilma, foi recriada, por meio da Portaria Interministerial nํㅜ 102, de 7 de abril, o Comitê de Monitoramento e Avaliaçáo de Políticas Públicas, com o objetivo de aperfeiçoar as políticas públicas e aprimorar a alocação de recursos e melhorar a qualidade do gasto público. A partir daí, e ligada à agenda de governança pública, que será apresentada adiante, a avaliação ganha destaque no Núcleo de Governo, acompanhando o processo de aproximação do Brasil à Organização para a Cooperação e Desenvolvimento Econômico (OCDE), tendo sido produzidos guias para aplicação de metodologias de análise ex ante, avaliação ex post e avaliação de impacto regulatório sob patrocínio da Casa Civil da Presidência da República, já durante o governo de Michel Temer, com justificativa centrada na crise fiscal (Brasil, 2018). Vale ressaltar que esses manuais retomavam o modelo lógico como referência para análise e elaboração das políticas públicas, técnica que tinha sido deixada em segundo plano a partir do PPA 2012-2015.

Em 2019, o Decreto no 9.834 transforma o comitê no Conselho de Monitoramento e Avaliação de Políticas Públicas (CMAP), com foco ainda mais voltado à análise do gasto, reforçando o seu viés fiscalista. O novo CMAP passou a ser composto por dois comitês: um de monitoramento e avaliação dos gastos diretos; e outro voltado aos subsídios da União.

A fragilização da capacidade de coordenação no âmbito do SPOF foi ainda reforçada por uma reestruturação organizacional que promoveu um rebaixamento gradativo do planejamento nos níveis hierárquicos do governo federal. Em um primeiro momento, em 2016, a então Secretaria de Planejamento e Investimentos Estratégicos do Ministério do Planejamento, Orçamento e Gestão foi fundida com a Assessoria Econômica do órgão. A Secretaria de Planejamento e Assuntos Econômicos, então oriunda dessa fusão, foi extinta em 2019, no início do governo Jair Bolsonaro, que recria o Ministério da Economia e posiciona a área de planejamento como uma subsecretaria dentro da estrutura da Secretaria de Avaliação, Planejamento, Energia e Loterias (SECAP), no guarda-chuva da Secretaria Especial de Fazenda.

A fragilização institucional do planejamento e o seu distanciamento do processo orçamentário teve reações dos órgãos de controle. Seu ativismo foi além das críticas às mudanças de metodologia do PPA, tendo papel central na reinterpretação de regras orçamentárias e na propositura da agenda de governança pública, definida como conjunto de mecanismos de liderança, estratégia e controle postos em prática para avaliar, direcionar e monitorar a gestão, com vistas à conduçáo de políticas públicas e à prestação de serviços de interesse da sociedade. Em certa medida, buscou substituir a agenda do planejamento, em franco declínio.

Em 22 de novembro de 2017, a partir de uma agenda proposta pelo Tribunal de Constas da União, o governo federal publicou o Decreto no 9.203, que dispóe sobre a política de governança da administração pública federal direta, autárquica e fundacional. Na mesma linha, apresenta ao Congresso Nacional o Projeto de Lei (PL) no 9.163/2017, que segue a mesma lógica do decreto, buscando ampliar seu alcance para além do Poder Executivo federal.

A principal novidade do PL está na tentativa de regulamentação do art. 174 da Constituição Federal, que no seu parágrafo primeiro determina que "A lei estabelecerá as diretrizes e bases do planejamento do desenvolvimento nacional equilibrado, o qual incorporará e compatibilizará os planos nacionais e regionais de desenvolvimento" (Brasil, 1988). Segundo o PL, o planejamento 
do desenvolvimento nacional equilibrado será composto pelos seguintes instrumentos: a estratégia nacional de desenvolvimento econômico e social; os planos nacionais, setoriais e regionais; e o PPA da União.

Embora o PL não tenha sido apreciado no Congresso Nacional, o Poder Executivo elaborou, em 2018, a Estratégia Nacional de Desenvolvimento Econômico e Social, para o horizonte de doze anos, ou três PPAs. Em direçáo contrária, no final de 2019, o novo governo encaminha a PEC no 188/2019, que, entre outros, prevê a extinçáo do PPA e transforma o orçamento anual em uma peça plurianual. No entanto, considerando o baixo vínculo atual entre PPA e orçamento, náo se pode afirmar que um instrumento de mais largo prazo, com um nível de generalidade e agregaçóes ainda maiores, consiga ser efetivo na orientação das decisôes alocativas de curto prazo no orçamento.

Ainda assim, em 26 de outubro de 2020, o governo federal publicou o Decreto no 10.531 , que institui a Estratégia Federal de Desenvolvimento para o Brasil no período de 2020 a 2031. A substituição dos termos nacional para federal, mais do que figura de linguagem, revela a ausência de diálogo federativo e com a sociedade civil na construção da estratégia, contrariando as diretrizes da própria política de governança, que previa a participação da sociedade nos instrumentos de planejamento.

Vale dizer que, reforçando a substituição da agenda de planejamento pela agenda de governança, a fragilização institucional do planejamento também alcançou outras estruturas governamentais responsáveis por essa agenda de planejamento de mais longo prazo e articulação com a sociedade civil. A Secretaria de Assuntos Estratégicos da (SAE), criada em 2007 e ligada à Presidência da República, com status de ministério, foi extinta em 2015, e, durante esse período, o Ipea esteve vinculado a ela. Por seu turno, o Conselho de Desenvolvimento Econômico e Social (CDES), criado em 2003, que poderia fazer uma interlocução com a sociedade civil para a construção da estratégia de longo prazo, foi extinto em 2019.

Enquanto a extinção do PPA não era aprovada - as PECs foram apresentadas em novembro de 2019 -, a discussão em torno do PPA 2020-2023 se iniciou também buscando um esvaziamento do plano, ao tentar excluir a necessidade de que os investimentos plurianuais constassem do PPA para que pudessem ter sua execução iniciada. De outro lado, o PPA 2020-2023 retomou, ainda que com adaptaçôes que limitam sua correta aplicação, o modelo lógico para a construção dos programas, bem como apostou na aproximação do planejamento com a avaliação, tendo seu decreto de gestáo (Decreto no 10.321/2020) previsto a integração dos processos avaliativos com o CMAP (Couto e Cardoso Júnior, 2020).

A autonomização do orçamento em relação ao planejamento se complementa com propostas de desvinculação do orçamento com a apresentação de novas PECs, ao final de 2019, que alterariam, uma vez mais, as normas orçamentárias. De um lado, flexibilizam os mínimos constitucionais, permitindo a compensação de gastos de educação com gastos em saúde, e vice-versa, e, de outro lado, propóem a extinção de fundos setoriais com receitas vinculadas.

Em suma, ao longo do curso da última década, em cujo início o planejamento setorial robustecido era acompanhado por uma fragilidade na capacidade de coordenação do sistema de planejamento, a estrutura organizacional de planejamento governamental e seu principal instrumento de médio prazo são objetos de esvaziamento estratégico e institucional. Isso se reflete em um distanciamento maior com relação às peças orçamentárias, que preservam os gastos financeiros, observam um enrijecimento 
dos gastos primários e são objetos de maior incidência do Poder Legislativo. O ocaso do planejamento é seguido pelo fortalecimento de uma agenda de governança, intimamente relacionada ao controle, e a proximidade entre planejamento e avaliação marcada explicitamente pela agenda de corte de gastos.

\section{OLHAR DA DIEST SOBRE OS CAMINHOS DO PLANEJAMENTO GOVERNAMENTAL}

O tema do planejamento governamental é um tema tradicional de estudos e análise do Ipea, central na produção da Diest/Ipea nesses dez primeiros anos de existência, que tem acompanhado esse movimento com um distanciamento engajado. Foram levantados vários alertas e indicaçóes alternativas para a institucionalidade do setor, inclusive no que se refere às escolhas metodológicas do próprio PPA.

A preocupação com a trajetória do planejamento (no Brasil e na América Latina, em particular) esteve presente desde os primeiros anos da diretoria (Lavalle, 2010). Rezende (2010) descreve os momentos de auge, declínio e reconstrução do planejamento no Brasil, em linha com a retomada dessa atividade observada durante os anos 2000. Para a sua reconstrução, o autor apontava as necessidades de aprimoramento do PPA e de sua relação com o orçamento, inclusive defendendo a junção da Secretaria de Orçamento Federal com a Secretaria de Planejamento, com a finalidade de se ter um maior controle da execução do orçamento em linha com as prioridades de governo, além do fortalecimento do próprio sistema de planejamento e orçamento federal, considerando aí a capacitação das unidades setoriais e de seus servidores. Por fim, o autor alerta também para a hipertrofia dos órgãos de controle.

Um aspecto que Rezende (2010) considera marginalmente é o da participação social, que acabou sendo um dos temas que mais receberam atenção da Diest/Ipea. Refletindo a experiência dos anos anteriores, Cohn (2010) aponta os seus limites, ou "constrangimentos à utopia da participação social como democratização imediata da gestão pública” (Cohn, 2010, p. 23). Na mesma linha, uma série de livros de 2010, Brasil em Desenvolvimento, que buscava sintetizar a posição institucional, trazia artigos sobre as instâncias de participação social, marcando sua heterogeneidade e reafirmando que "a mera existência e operação formal destas instituiçôes não implicam necessariamente a realização de seu pleno potencial democrático” (Ipea, 2010, p. 582). Nessa linha, vale destaque também Cardoso Júnior, Santos e Alencar (2010), que buscaram refletir sobre a trajetória do Conselho de Desenvolvimento Econômico Social (CDES) durante o governo Lula, discutindo essa inovação institucional sob a insígnia do planejamento democrático. Toda essa produção buscou não apenas compreender as complexidades das relaçôes socioestatais, mas também conferir maior efetividade ao processo participativo no planejamento. ${ }^{6}$

Da mesma forma, as reflexões a respeito da trajetória do planejamento governamental foram também uma constante na produção da Diest. Nesta safra, além do trabalho de Rezende (2010), se destacam os autores José Celso Cardoso Júnior e Ronaldo Coutinho Garcia. A coleção Pensamento Estratégico, Planejamento Governamental \& Desenvolvimento no Brasil Contemporâneo produziu quatro livros que refletiram sobre a evolução do planejamento e as relaçóes entre desenvolvimento, planejamento, gestão - incluindo avaliação de políticas públicas - e participação social - alcançando também as experiências estaduais em torno do PPA 2012/2015.

6. Ver, entre outros, Pires e Vaz (2012); Silva e Deboni (2012); Souza (2012); Cunha (2012); Avritzer (2012); Avritzer e Souza (2013); Amaral (2014); Lima et al. (2014); Avelino, Alencar e Costa (2017); e Silva (2018). 
Nessa coleção, um livro foi dedicado ao PPA 2012/2015 do governo federal, no qual se ressaltam as inovações metodológicas do novo plano, sob a insígnia de experimentalismo institucional. Ainda incipiente em um Estado marcado por um pragmatismo acentuado, esse experimentalismo buscado no PPA teria enfrentado grande resistência burocrática em assimilar novas práticas necessárias para pôr em marcha um ativismo estatal necessário para carrear o desenvolvimento nacional em um ambiente democrático (Cardoso Júnior e Santos, 2015). Mais do que alterar o PPA, seria necessário, portanto, uma reflexão mais robusta sobre o próprio Estado.

No entanto, o Ipea não deixou de abrir espaço para críticas às alterações da metodologia do PPA. $\mathrm{Na}$ mesma coleção, um livro dedicado à reflexão de planejamento e avaliação de políticas públicas (Cardoso Júnior e Cunha, 2015), baseado mormente na produção de Ronaldo Garcia e Martha Cassiolato, argumentava que o PPA 2012-2015 não conseguiria superar os problemas observados nos PPAs anteriores. Mas ia além, indicando possibilidades futuras para a institucionalidade do Sistema de Planejamento e de Orçamento Federal e também para o próprio plano. Destaca-se, nessa linha, o resgate da importância das práticas avaliativas de políticas públicas, principalmente a partir da utilização do modelo lógico, metodologia aprimorada no Ipea para aplicaçáo na melhoria dos desenhos dos programas de governo a partir da conjugação de técnicas de diferentes origens.

As fragilidades não superadas do PPA - conjugadas com o processo de fragilização do planejamento governamental como um todo, unidas ao maior espaço dos órgáos de controle, conforme alertado nas pesquisas do próprio Ipea - abriram caminho para a agenda da governança. Nesse ponto, a Diest/Ipea, cumprindo com sua missão de assessoramento ao Estado, contribuiu criticamente com a construção do Guia da Política de Governança Pública, complementado com uma publicação temática do Boletim de Análise Política Institucional, organizado por Pedro Cavalcante e Roberto Pires, sobre o tema. A intenção dos organizadores era justamente alertar para os perigos de uma abordagem restrita e prescritiva, recuperando, em contraposição, "a multidimensionalidade do conceito de governança e, sobretudo, suas potenciais contribuiçóes para a construção de capacidades de ação no setor público brasileiro" (Cavalcante e Pires, 2018, p. 6).

Na mesma linha, a Diest/Ipea contribui com a elaboração dos guias de análise ex ante de políticas públicas, no momento em que o governo buscava fortalecer a sua agenda de avaliação. À criação do CMAP, em 2016, seguiu-se, na mesma linha da política de governança, um processo de manualização das práticas de avaliação. Utilizou-se da técnica do modelo lógico para o Guia que deveria nortear as proposições de novas políticas setoriais a serem submetidas à apreciação da Casa Civil.

Aproveitando-se dessa trajetória, o recém-criado Ministério da Economia recuperou a referência do modelo lógico, com adaptaçôes que visavam sua simplificação, para a elaboração do PPA 2020-2023, apresentando inovações metodológicas com relação aos dois PPAs anteriores. A produção da Diest/Ipea não deixou de saudar a nova proposição, mas o fez destacando suas limitaçóes e indicando os perigos do esvaziamento do plano (Couto e Cardoso Júnior, 2020a).

Nessa linha, o olhar crítico da Diest/Ipea reconhece a fragilidade atual do planejamento governamental e de seu principal instrumento. No livro Instituiçôes e Desenvolvimento no Brasil, já de 2020, três artigos discutiram a relação entre planejamento e desenvolvimento, recuperando o histórico dos instrumentos de planejamento; as ideias que se projetaram nas suas estratégias recentes a partir das relaçóes entre desenvolvimento nacional e superação das desigualdades sociais; e suas 
limitaçóes para que consiga efetivamente incidir nas decisóes alocativas de curto prazo (Kliass, 2020; Pinheiro, 2020; Couto, 2020).

Nesse ponto, recupera-se um tema tradicional do Ipea quando este abrigava, até os anos 1980, o Instituto de Orçamento (INOR), instituição que deu origem à Secretaria de Orçamento Federal (Garcia, 2015a). As tentativas de compreensão e aprimoramentos da institucionalidade do planejamento passam a se estender a toda a governança orçamentária, abrindo uma nova agenda de pesquisa que busca compreender náo apenas as ligaçóes entre plano-orçamento, mas como os governos orientam as peças orçamentárias às suas prioridades dentro do enquadramento democrático e como as regras que emolduram as relações no âmbito do processo decisório do gasto público favorecem ou dificultam o posicionamento e o comportamento dos atores que disputam o orçamento.

Nessa linha, o Ipea, e a Diest em particular, resistem como instituição inserida no sistema de planejamento e orçamento federal, promovendo reflexôes e indicação de políticas que fortaleçam as suas dimensóes político-estratégicas e institucionalidades. ${ }^{7}$ Mais do que uma questáo de autopreservação, trata-se de reafirmar uma visão histórica a respeito da importância das atividades de planejamento estatal para que qualquer governo, com seus próprios vieses ideológicos e filosofias políticas, dentro do enquadramento do Estado Democrático de Direito, tenha maiores capacidades de implementar os programas que a sociedade lhes outorgou.

\section{CONCLUSÃO}

$\mathrm{O}$ artigo apresentou a produção da Diest/Ipea sobre o tema do planejamento governamental em um contexto de fragilização institucional, ou seja, pesquisas e estudos sobre diversos aspectos do planejamento, dialogando diretamente com a evoluçáo institucional descrita e analisada.

Cabe destacar que esse processo de fragilização institucional ainda oferece amplas oportunidades para a continuidade dessa linha de pesquisa no âmbito da Diest/Ipea, seja na melhor compreensão das suas origens, causas e consequências, seja para discutir a incidência do planejamento nas decisóes alocativas e de gestão das políticas públicas, nas suas funçóes de Núcleo de Governo e papéis a serem desempenhados para a definição dos próprios rumos do desenvolvimento do país nos cenários posteriores à grave crise causada pela pandemia da Covid-19.

\section{REFERÊNCIAS}

ABERS, R. N. Conflitos, mobilizaçóes e participação institucionalizada: a relação entre a sociedade civil e a construção de grandes obras de infraestrutura. Brasília: Ipea, 1996. (Texto para Discussão, n. 2231).

ALBUQUERQUE, E. B.; COUTO, L. F. Território, participação e planejamento: genda de Desenvolvimento Territorial e o caso do Rio Grande do Sul. In: MONTORO, G. C. F. et al. (Org.). Um olhar para o desenvolvimento territorial: Sul. Rio de Janeiro: BNDES, 2014. v. 1. p. 248-268.

7. Vale lembrar que institutos semelhantes ao Ipea nos governos estaduais vêm sofrendo processos de retração ou mesmo extinção. 
AMARAL, L. A. Participaçáo social e conteúdo estratégico nos PPAs estaduais. Brasília: Ipea, 2014. (Texto para Discussão, n. 1998).

AVELINO, D. P. de; ALENCAR, J. L. O.; COSTA, P. C. B. Colegiados nacionais de políticas públicas em contexto de mudanças: equipes de apoio e estratégias de sobrevivência social. Brasília: Ipea, 2017. (Texto para Discussão, n. 2340).

AVRITZER, L. Conferências nacionais: ampliando e redefinindo os padróes de participação social no Brasil. Brasília: Ipea, 2012. (Texto para Discussão, n. 1739).

AVRITZER, L.; SOUZA, C H. L. de. Conferências nacionais: atores, dinâmicas participativas e efetividade. Ipea, Brasília, 2013.

BRASIL. Constituição da República Federativa do Brasil. Brasília, DF: Senado Federal: Centro Gráfico, 1988. 2018. v. 1.

Avaliação de políticas públicas: guia prático de análise ex ante. Brasília: Casa Civil; Ipea,

CARDOSO JÚNIOR., J. C.; CUNHA, A. (Orgs.). Planejamento e avaliaçáo de políticas públicas. Brasília: Ipea, 2015.

CARDOSO JÚNIOR J. C.; GIMENEZ, D. M. Crescimento econômico e planejamento no Brasil (2003-2010): evidências e possibilidades do ciclo recente. In: CARDOSO JÚNIOR, J. C. (Org.). A reinvençáo do planejamento governamental no Brasil. Brasília: Ipea, 2011.

CARDOSO JÚNIOR J. C.; SANTOS, E. V. dos. PPA 2012-2015: experimentalismo institucional e resistência burocrática. Ipea, Brasília, 2015. v. 2.

CARDOSO JÚNIOR J. C.; SANTOS, J. C. dos; ALENCAR, J. L.O. Diálogos para o desenvolvimento: a experiência do Conselho de Desenvolvimento Econômico e Social sob o governo Lula. Brasília: Ipea, 2010.

CARDOSO JÚNIOR J. C.; SANTOS, J. C. dos; PIRES, R. R. PPA 2012-2015: experiência subnacional de planejamento no Brasil. Brasília: Ipea, 2015. v. 3.

CAVALCANTE, P. L. C.; PIRES, R. Apresentação: variedades de governança pública. Boletim de Análise Político-Institucional, n. 19, 2018.

COHN, A. Participação social e conselhos de políticas públicas. Brasília: Ipea, 2010. (Texto para Discussão, n. 1547).

COUTO, L. F. A institucionalidade de planejamento e orçamento e o papel do PPA na governança orçamentária. In: MAGALHÃES, L. C. G.; PINHEIRO, M. M. S. Instituiçóes e desenvolvimento no Brasil: diagnósticos e uma agenda de pesquisas para as políticas públicas. Brasília: Ipea, 2020.

COUTO, L. F.; CARDOSO JÚNIOR. J. C. Governança orçamentária: transformaçóes e lacunas nas práticas de planejamento e orçamento no Brasil. Boletim de Análise Político-Institucional, n. 19, 2018.

. A função dos Planos Plurianuais no direcionamento dos orçamentos anuais: avaliação da trajetória dos PPAs no cumprimento da sua missão constitucional e o lugar do PPA 2020-2023. Brasília: Ipea, 2020a. (Texto para Discussão, n. 2549). 
. Planejamento governamental a partir da Reforma do Estado. In: CAVALCANTE, P.; SILVA, M. S. Reformas do Estado no Brasil (1995-2020): trajetórias, inovaçóes e desafios. Ipea, 2020 b. COUTO, L. F.; MAGALHÂES JÚNIOR, A. P. de. Iniciativas, funçôes e estruturas de planejamento federal. Boletim de Análise Político-Institucional, n. 12, 2017.

- Gestão de prioridades e Núcleo de Governo: os casos do Brasil em ação e do programa de aceleração do crescimento. In: CAVALCANTE, P. L. C.; GOMIDE. A. A. (Org.). O presidente e seu núcleo de governo: a coordenação do Poder Executivo. Ipea, Brasília, 2018.

CUNHA, E. S. C. Conferências de políticas públicas e inclusão participativa. Brasília: Ipea, 2012. (Texto para Discussão, n. 1733).

DE TONI, J. Agenda estratégica, planejamento e programas eleitorais: cálculo político e pragmatismo. In: CAVALCANTE, P. L. C.; GOMIDE. A. A. (Org.). O presidente e seu núcleo de governo: a coordenação do Poder Executivo. Ipea, Brasília, 2018.

GARCIA, R. C. A reorganização do processo de planejamento do governo federal: o PPA 2000-2003. In: CARDOSO JÚNIOR, J. C.; CUNHA, A. (Org.). Planejamento e avaliaçáo de políticas públicas. Brasília: Ipea, 2015a.

. PPA: o que não é e o que pode ser. In: CARDOSO JÚNIOR, J. C.; CUNHA, A. (Org.). Planejamento e avaliação de políticas públicas. Brasília: Ipea, $2015 \mathrm{~b}$.

IPEA - INSTITUTO DE PESQUISA ECONÔMICA APLICADA. Brasil em desenvolvimento: Estado, planejamento e políticas públicas. Brasília: Ipea, 2010. v. 3.

KLIASS, P. Planejamento do desenvolvimento econômico e Plano Plurianual no Brasil. In: MAGALHÁES, L. C. G. e PINHEIRO, M. M. S. Instituiçóes e desenvolvimento no Brasil: diagnósticos e uma agenda de pesquisas para as políticas públicas. Ipea, Brasília, 2020.

LAVALLE, J L. Instituciones e instrumentos para el planeamiento gubernamental en América Latina. Brasília: Cepal, Ipea, 2010. (Texto para Discussão, n. 005).

LIMA, P. P. F. et al. Conselhos Nacionais: elementos constitutivos para sua institucionalização. Brasília: Ipea, 2014. (Texto para Discussão, n. 1951).

MAGALHÁES JÚNIOR, Á. P. de. RS 2030: uma Agenda de Desenvolvimento Territorial à procura de um Planejamento Nacional. Revista Brasileira de Planejamento e Orçamento, v. 6, n. 1, 2016. MAGALHÃES, L. C. G.; PINHEIRO, M. M. S. Instituiçóes e desenvolvimento no Brasil: diagnósticos e uma agenda de pesquisas para as políticas públicas. Ipea, Brasília, 2020.

PINHEIRO, M. M. S. Desenvolvimento, planejamento e combate às desigualdades no Brasil: notas sobre o papel das instituiçóes a partir das contribuiçóes teóricas de Celso Furtado e Amartya Sem. In: MAGALHÁES, L. C. G.; PINHEIRO, M. M. S. (Org.). Instituiçóes e desenvolvimento no Brasil: diagnósticos e uma agenda de pesquisas para as políticas públicas. Brasília: Ipea, 2020.

PIRES, R.; VAZ, A. Participaçáo social como método de governo? um mapeamento das "interfaces socioestatais" nos programas federais. Brasília: Ipea, 2012. (Texto para Discussão, n. 1707).

REZENDE, F. Planejamento no Brasil: auge, declínio e caminhos para a reconstrução. Brasília: Ipea, 2010. (Texto para Discussão, n. 1522). 
RODRIGUES, J. A. M.; XAVIER, E. de M. A transversalidade e os Planos Plurianuais: a história contada por três ciclos de elaboração e gestão do plano federal. Revista Brasileira de Administraçáo Política, v. 10, n. 2, out. 2017.

SANTOS, E. V. dos; VENTURA, O.; NETO, R. PPA, LDO e LOA: disfunçóes entre o planejamento, a gestão, o orçamento e o controle. In: CARDOSO JÚNIOR, J. C.; SANTOS, E. V. dos. PPA 2012-2015: experimentalismo institucional e resistência burocrática. Brasília: Ipea, 2015.

SILVA, F. S e; DEBONI, F. Participação social e governança democrática na segurança pública: possibilidades para a atuação do Conselho Nacional de Segurança Pública. Brasília: Ipea, 2012. (Texto para Discussão, n. 1714).

SILVA, S. P. Democracia, políticas públicas e instituiçóes de deliberação participativa: visões sobre a experiência brasileira. Brasília: Ipea, 2018. (Texto para Discussão, n. 2358).

SOUZA, C. H. L. de. A que vieram as Conferências Nacionais? Uma análise dos objetivos dos processos realizados entre 2003 e 2010. Brasília: Ipea, 2012. (Texto para Discussão, n. 1718). 